Provided for non-commercial research and education use. Not for reproduction, distribution or commercial use.

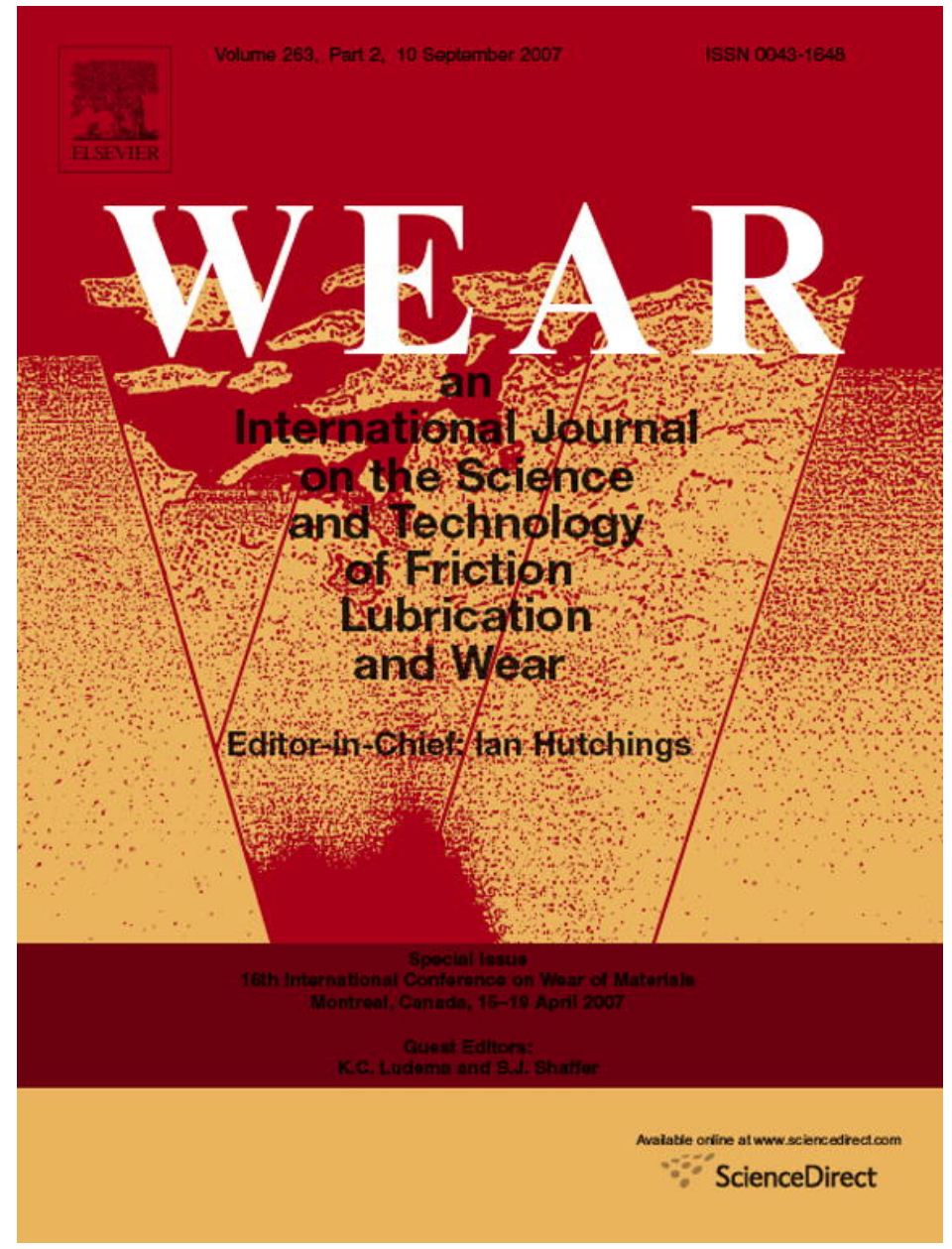

This article was published in an Elsevier journal. The attached copy

is furnished to the author for non-commercial research and education use, including for instruction at the author's institution, sharing with colleagues and providing to institution administration.

Other uses, including reproduction and distribution, or selling or licensing copies, or posting to personal, institutional or third party websites are prohibited.

In most cases authors are permitted to post their version of the article (e.g. in Word or Tex form) to their personal website or institutional repository. Authors requiring further information regarding Elsevier's archiving and manuscript policies are encouraged to visit: 


\title{
Electrostatic wear monitoring of rolling element bearings
}

\author{
T.J. Harvey ${ }^{\text {a,* }}$, R.J.K. Wood ${ }^{\text {a }}$, H.E.G. Powrie ${ }^{\text {b,1 }}$ \\ a School of Engineering Sciences, University of Southampton, Southampton, Hampshire SO17 1BJ, UK \\ b Smiths Aerospace Information Systems, School Lane, Eastleigh, Hampshire SO53 4YG, UK \\ Received 8 September 2006; received in revised form 19 December 2006; accepted 21 December 2006 \\ Available online 23 May 2007
}

\begin{abstract}
Research and development work at the University of Southampton using an electrostatic condition monitoring system developed by Smiths Aerospace Information Systems has shown that electrostatic charge signals can be used to detect the onset of wear in lubricated tribo-contacts. Preliminary investigations have already demonstrated the viability of this system when tested on a laboratory-based pin-on-disc rig, a reciprocating laboratory wear rig and in an FZG gear scuffing rig. These preliminary experiments have indicated several charging mechanisms may be involved, namely - tribo-charging, localised surface charge variations, exo-emissions and debris generation.

The electrostatic monitoring system has now been implemented on a taper-roller bearing test rig. The electrostatic system employed comprises three wear-site sensors (WSS) and an oil-line sensor (OLS). The WSS are mounted close to the bearing in order to monitor the earliest stages of component surface breakdown and wear, whereas the OLS is placed in the re-circulation oil-line to monitor debris generated and transported from the deteriorating component. For the present tests, taper-roller bearing wear was monitored using electrostatic sensors as well as vibration and lubricant temperature measurements; also two additional oil-line monitoring devices, supplied by Macom Technology Ltd., using Eddy current technology and ferromagnetism to sense debris entrained in the lubricant recirculating system were employed.

The experimental data shows that the electrostatic monitoring systems detected bearing deterioration up to $4 \mathrm{~h}$ prior to complete failure (seizure) during a seeded fault test. The electrostatic wear-site and oil-line sensors detected changes in charge that coincided with increases in vibration, temperature and debris generation detected by the two Macom units.
\end{abstract}

(C) 2007 Elsevier B.V. All rights reserved.

Keywords: Taper roller bearings; Condition monitoring; Vibration; Electrostatics

\section{Introduction}

Condition monitoring system offers the ability to reduce maintenance costs, increase machinery availability (lower downtime) and avoid catastrophic failure; an example of catastrophic bearing failure is shown by reference [1]. A concise review of condition monitoring techniques has been conducted by Barron [2] and Neale [3].

Condition monitoring can be divided into on-line (real-time) and off-line systems. Off-line systems, such as spectrometric oil analysis (SOA), optical microscopy, energy dispersive X-ray, may be used to analyze debris or oil samples captured during machinery operation. Such systems allow sophisticated analy-

\footnotetext{
* Corresponding author. Tel.: +44 2380594 881; fax: +44 2380593230.

E-mail addresses: harveyt@soton.ac.uk (T.J. Harvey), honor.powrie@smiths-aerospace.com (H.E.G. Powrie).

1 Tel.: +44 238024 2014; fax: +44 2380242001.
}

sis of samples; however, they require greater logistical support, trained personnel and need to be implemented on a regular basis in order to be useful. On-line systems currently include electric chip detectors, inductive devices, vibration and acoustic emission analyses. Chip detectors have limited capability with poor capture efficiency, no debris trending with time and insensitivity to non-ferrous debris being some of the drawbacks. Inductive devices detect metallic debris but are insensitive to smaller particulate, debris sizes typically $>100 \mu \mathrm{m}$ ferrous, $>250 \mu \mathrm{m}$ metallic (non-ferrous) debris [4].

Bearing monitoring has received considerable attention as the majority of the problems with rotating machinery are caused by faulty bearings [5]. The most common cause of failure in bearings is fatigue cracking, due to the heavily loaded Hertzian contact zones employed [6], which creates localized defects such as cracks, pits and spalls on the rolling surfaces.

Tandon and Choudhury [7] recently reviewed vibration and acoustic measurements, the most common techniques employed 
and found two approaches had been adopted by researches for studying localized defects on bearings, the first approach runs the bearing until failure and monitor the changes in response. Failure was usually accelerated by overloading, overspeeding or starving the bearings of lubricant. This approach of life testing is quite time-consuming. The second approach was to intentionally introduce defects in the bearings, by techniques such as acid etching, spark erosion, scratching or mechanical indentation, and then measure the vibration/acoustic emission response and compare it with that of good bearings. The testing of bearings with simulated defects is much quicker but preparation of the defective bearings requires special techniques [7].

Recently a new condition monitoring technique has been developed based on electrostatic charge generation on contact deterioration, this technique was originally developed for detection of debris in the gas path of jet engines and gas turbines [8-10]. The fundamental principle is to detect the electrostatic charge associated with the debris present in the gas path. Changes in the charge level can then be related to the presence of increased amounts of debris and hence the onset of gas path component deterioration. The advantage of this technique is that it measures a direct product of the fault, rather than secondary effects, such as increased vibration or temperature exceedance. Thus, it is a useful tool for early detection and progressive monitoring of component deterioration. This is particularly pertinent for machinery prognostics and health management, which requires system diagnostic information over a broad range of component conditions.

Collaborative work by the University of Southampton and Smiths Aerospace has applied electrostatic monitoring to oil systems. Previous investigations have already demonstrated the viability of this system when tested on a laboratory-based pinon-disc rig, a reciprocating laboratory wear rig [4,11-14], an FZG gear scuffing rig $[15,16]$ and roller bearing testing on a F100 jet engine [17-19].

The general aim of the present work at the University of Southampton is to investigate the use of electrostatic monitoring for taper roller bearing applications. The rig, which has been refurbished and extensively modified, consists of a test chamber, a drive motor, hydraulic loading system and oil recirculation pipe-work. The test chamber has been modified to accommodate three electrostatic wear-site sensors in close proximity to the bearings. An electrostatic oil-line sensor has been installed in the recirculation system to monitor any debris produced during testing. The test chamber houses four taper-roller bearings; two support and two test bearings.

In addition to the electrostatic monitoring of both the wearsite and oil-line, vibration monitoring has been employed to corroborate detection of bearing deterioration. Also employed are two additional on-line debris monitoring devices, supplied by Macom Technology Ltd., the TA10 and TA20 using Eddy current technology and ferromagnetism, respectively to sense debris entrained in the lubricant recirculating system.

This paper details experimental results from an accelerated bearing failure test under overloaded and seeded fault conditions.
Table 1

Running conditions of accelerated test and bearing specifications

\begin{tabular}{ll}
\hline General & \\
Speed & $2500 \mathrm{rpm}$ \\
Maximum load & $20 \mathrm{kN}(\sim 200 \%$ max. dynamic load $)$ \\
Lubricant & TRB $115-032$ \\
Lubricant flow rate & $41 \mathrm{~min}^{-1}$ \\
Bearings & \\
Bearing with artificial defect & $\# 2$ \\
Outer race & LM67010 \\
Cone & LM67048 \\
Contact angle & $13.5^{\circ}$ \\
Pitch diameter & 1.78 in. $(45.226 \mathrm{~mm})$ \\
Inner diameter & $1.25 \mathrm{in} .(31.75 \mathrm{~mm})$ \\
Outer diameter & $2.328 \mathrm{in} .(59.13 \mathrm{~mm})$ \\
Bearing width & $0.6467 \mathrm{in} .(14.43 \mathrm{~mm})$ \\
Rollers per row & 19 \\
Mean roller diameter & 0.2436 in. $(6.186 \mathrm{~mm})$ \\
\hline
\end{tabular}

\section{Experimental}

Experimental parameters used in the accelerated testing are shown in Table 1.

The bearings tested are taper roller bearings (LM67010 cup and LM67048 cone); see Table 1 for specifications. The rig contains four bearings, two support bearings are inserted in the two end housings and two test bearings are inserted in the centre housing (see Fig. 1). The two support housings have a precision fit in the test chamber, while the centre housing allows for deflection of the shaft during testing. The data presented is from an accelerated test using an artificial defect on test bearing \#2; details of this defect are described below. The test was also accelerated by overloading the test bearings, approximately $200 \%$ dynamic radial rating.

The artificial defect was induced by pre-indentation of the inner race, see Fig. 2. The artificial defect was applied with a Rockwell Hardness testing machine using a " $C$ " type diamond indenter. This applies a 150-kgf load with an included angle of $120^{\circ}$. Each cone (inner race) was mounted on a fixture such that the diamond was perpendicular to the race. The cone race has one dent at the centre of the raceway. An image of the modified surface profile of the pre-indentation is shown in Fig. 3 (courtesy of The Timken Company). Table 2 has been constructed from three such profiles. For the accelerated testing one of the test bearings (\#2) was replaced with a pre-indented bearing. The bearings are numbered from the drive end in a sequential manner, see Fig. 1.

Table 2

Pre-indentation surface profile parameters (PRp: peak height above surface plane, PRv: valley depth below surface plane; PRt $=P R p+P R v)$

\begin{tabular}{|c|c|c|c|c|}
\hline \multirow[t]{2}{*}{ Parameters } & \multicolumn{3}{|c|}{ Measurements $(\mu \mathrm{m})$} & \multirow[t]{2}{*}{ Average } \\
\hline & 1 & 2 & 3 & \\
\hline PRp & 6.44 & 7.74 & 6.56 & 6.91 \\
\hline PRv & 74.07 & 80.58 & 82.11 & 78.92 \\
\hline PRt & 80.51 & 88.36 & 88.67 & 85.83 \\
\hline
\end{tabular}




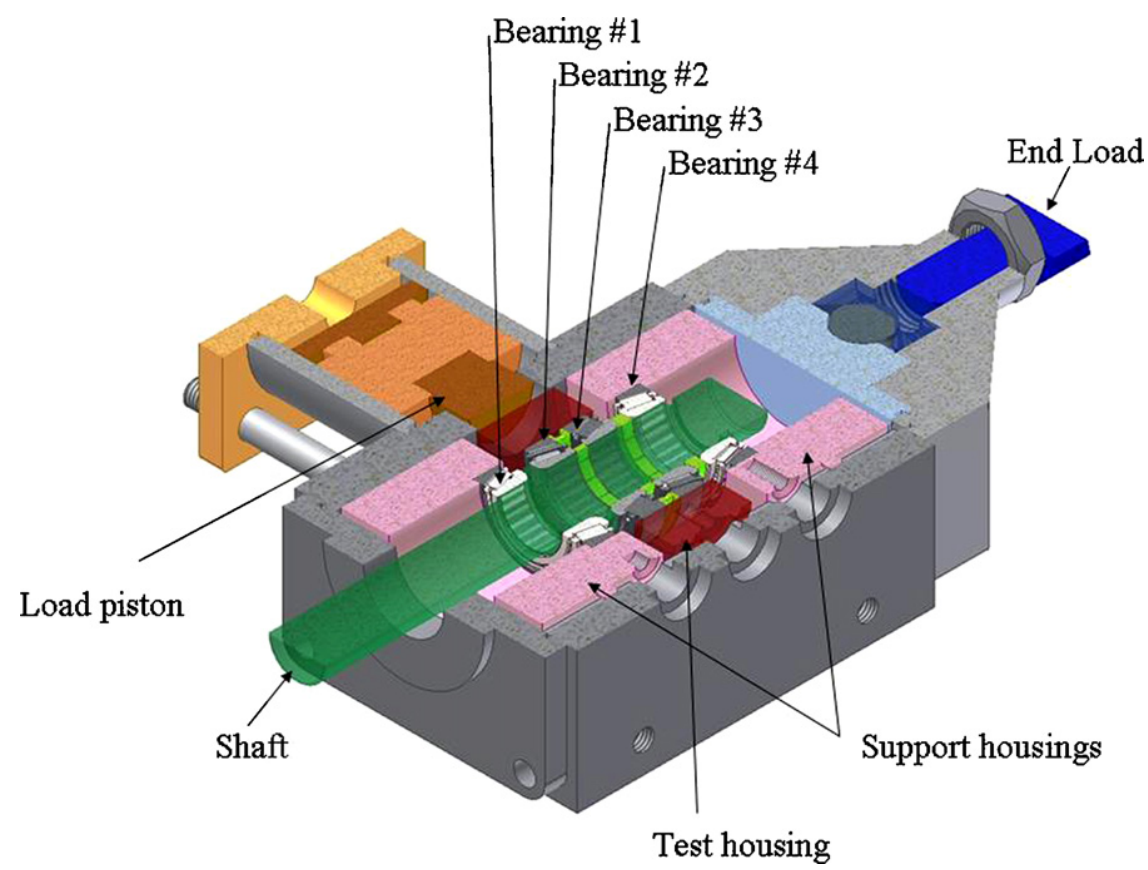

Fig. 1. Schematic showing the loading of the test bearings and position of vibration stalk, for simplicity the test chamber is not shown.

(a)

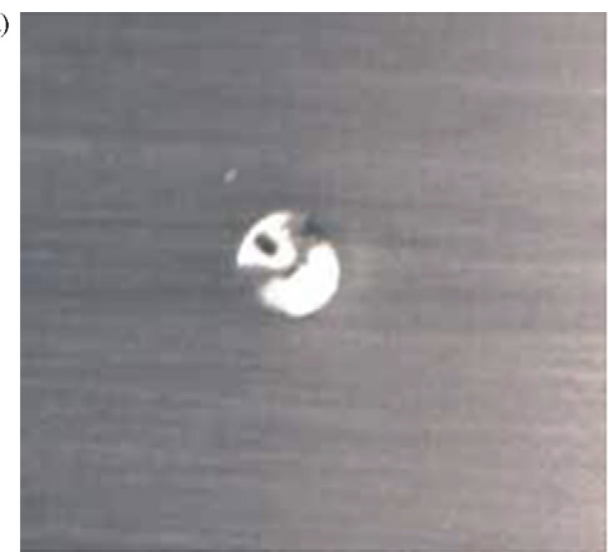

(b)

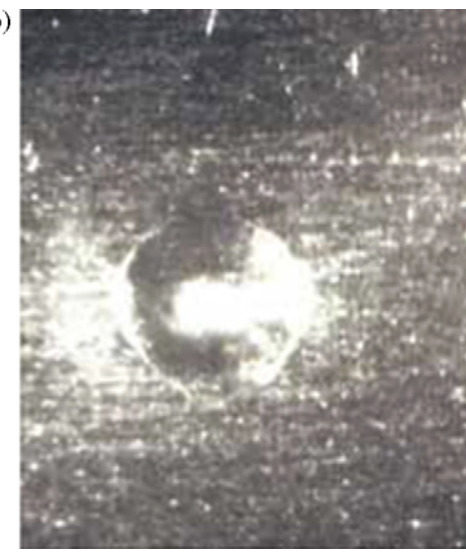

Fig. 2. Photographic Images of the pre-indent on the inner race at various magnifications: (a) $20 \times$ and (b) $40 \times$.

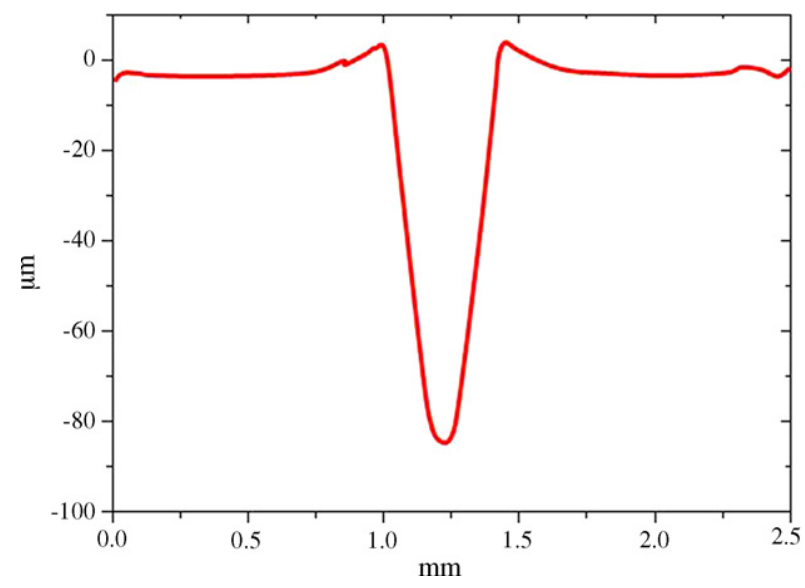

Fig. 3. Scanned image of pre-indent profile.
A hydraulic system applying pressure to a sealed piston assembly regulates the load on the bearings. This piston presses against the centre housing holding the two test bearings, as shown in Fig. 1. The loading system has two essential components: the manual hydraulic pump used to apply the pressure to the loading piston and the accumulator, which enables stabilisation of the hydraulic pressure applied to the loading piston. This ensures a constant force is applied to the bearings throughout the test.

The oil recirculation system (see Fig. 4) is connected together with copper and nylon pipework and brass connectors. The flow rate is controlled and monitored by the bypass system and a flowmeter. Heat generated by the bearing test rig is dissipated by a water-cooled heat exchanger. The oil recirculation system contains three filters: a paper filter of $25 \mu \mathrm{m}$ is positioned before the test housing, and a paper filter of $6 \mu \mathrm{m}$ is positioned after the test housing and before the oil pump; additional, to enable collection of ferrous debris produced during testing, a 


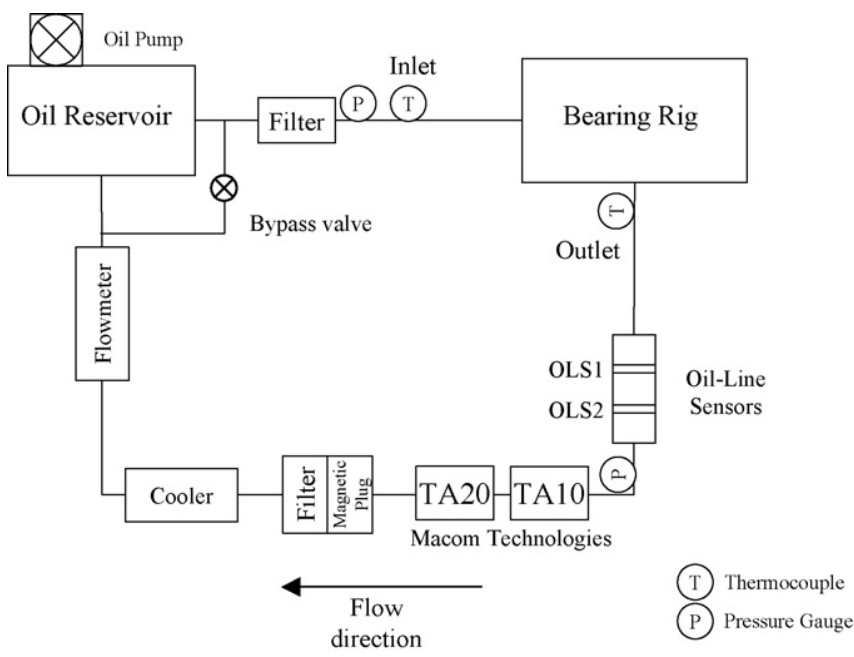

Fig. 4. Schematic of oil recirculation system (first filter is a $25 \mu \mathrm{m}$ and the second, next to magnetic plug, is $6 \mu \mathrm{m}$ ).

magnetic filter is placed just prior to the $(6 \mu \mathrm{m})$ second paper filter.

\subsection{Sensing technologies}

Four sets of monitoring devices were employed in testing, as follows: thermocouples, electrostatic sensing, vibration sensing and two Macom Technologies devices [20] measuring debris production.

Four precision fine bare wire K-type thermocouples were employed during testing; two to measure ambient conditions and two to measure oil temperature at the inlet and outlet of the test chamber have been inserted into the recirculating pipework, see Fig. 4.

The electrostatic sensors employed to monitor bearing performance are of two types. The first type is a wear-site sensor (WSS). As implied by its name the sensor monitors electrostatic

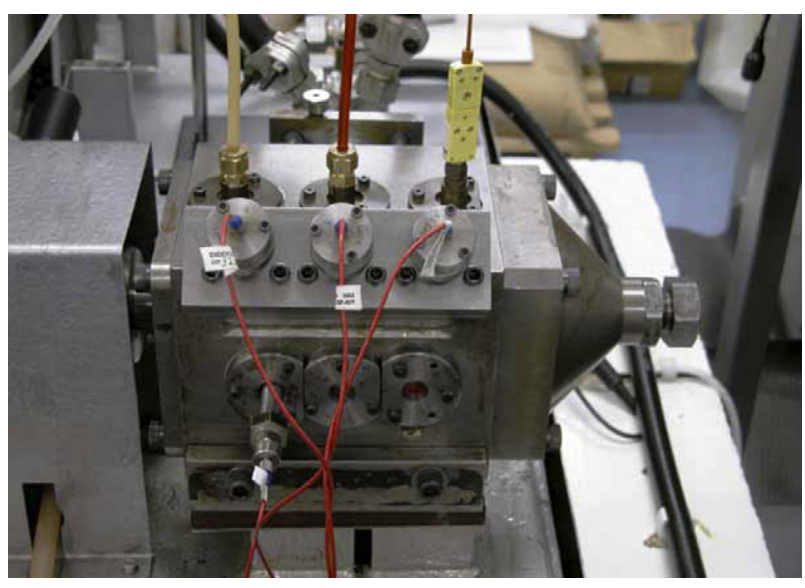

Fig. 6. Picture of test housing showing three electrostatic wear-site sensors and one vibration sensor.

charge in the vicinity of the bearing(s) and hence monitors the condition of potential wear-sites. The test rig has been modified to allow penetration of the wear-site sensor face close to the bearing. WSS 1 and WSS 3 monitor the two support bearings (bearings \#1 and \#4); WSS 2 monitors both test bearings (\#2 and \#3), as illustrated in Fig. 5. The second type of electrostatic sensor is the oil-line sensor (OLS). In general this consists of two identical ring sensors situated in the oil recirculation system, which monitors charge associated with debris generated during testing.

The bearing test rig is equipped with a single vibration sensor (see Fig. 6). The sensor is mounted on a vibration stalk installed on the front housing, containing the \#1 (support) bearing as shown in Fig. 1. The sensor is a piezoelectric type, with a sensitivity of $28.9 \mathrm{pC} \mathrm{g}^{-1}$.

Both the electrostatic and vibration sensors are connected to charge amplifiers via low-noise microdot cables. These amplifiers convert the charge signals to measurable voltage outputs that are fed into an A/D acquisition system. The charge ampli-

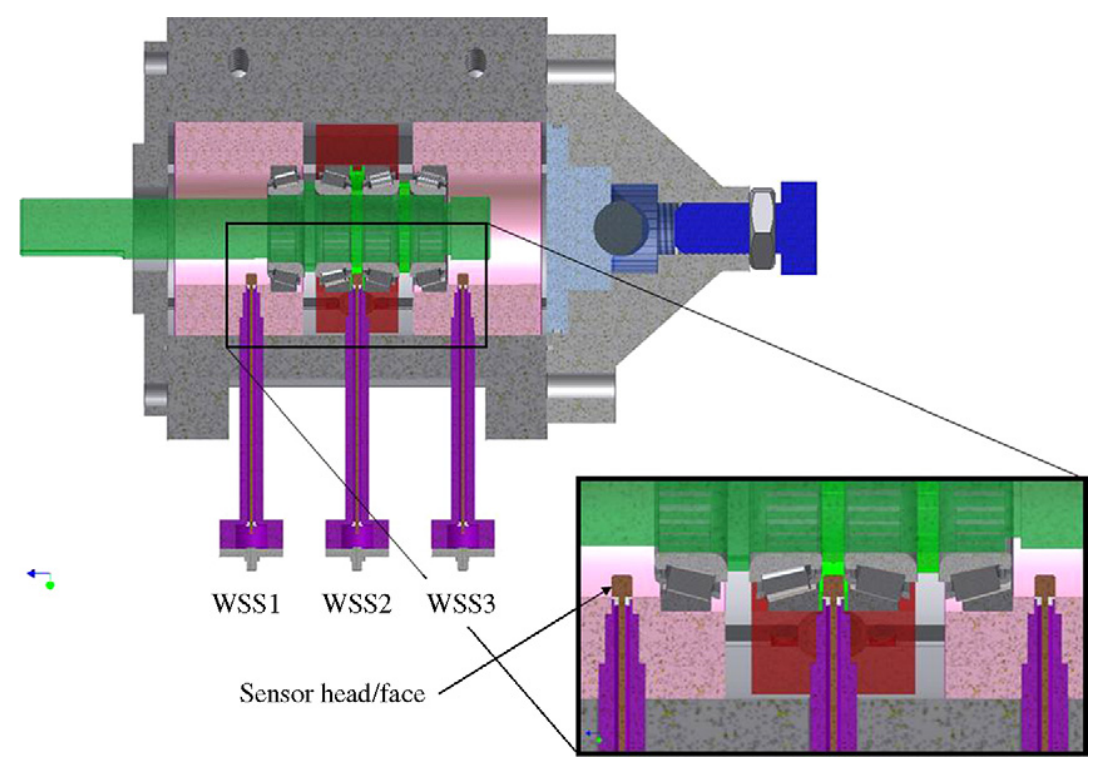

Fig. 5. Schematic diagram showing placement of electrostatic wear-site sensors (WSS) in housings. Diagram is at $45^{\circ}$ axial position to Fig. 1. 


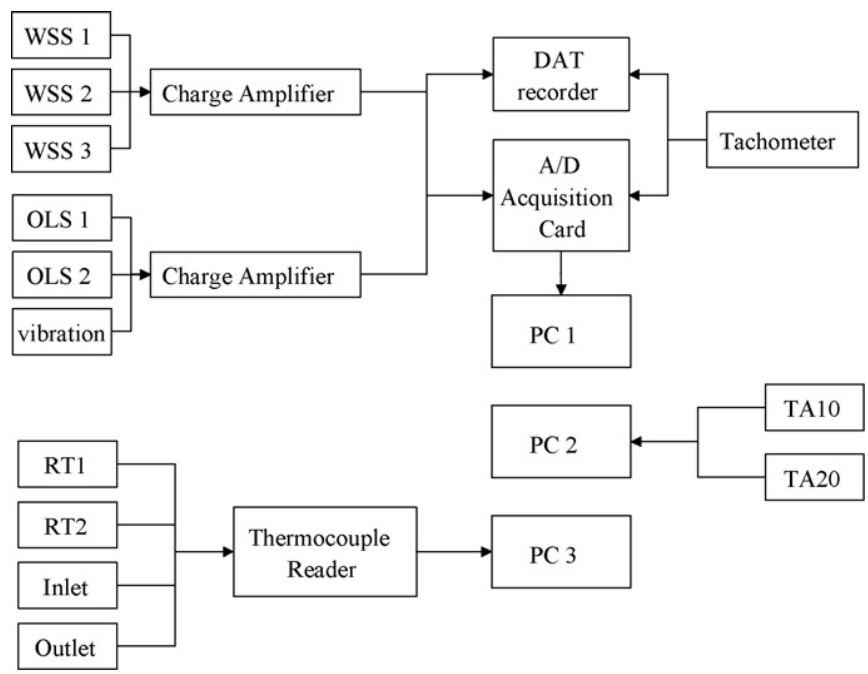

Fig. 7. Schematic of the interconnections of monitoring sensors and the acquisition systems.

fiers have a high-pass filter set at $1 \mathrm{~Hz}$, which eliminates dc-level drift, and a low-pass filter set at $10 \mathrm{kHz}$, that eliminates highfrequency noise.

The Macom TA10 operates by oil flowing through the transducer coil and any metallic particles present produce small changes in the inductance of the coil. Ferrous particles increase the inductance due to their high relative permeability, while nonferrous metallic particles reduce the inductance because of eddy currents induced in the particles. The signal amplitude gives a measure of particle size and concentration. The TA10 is sensitive to ferrous debris particles down to $100 \mu \mathrm{m}$ and non-ferrous metallic particles down to $200 \mu \mathrm{m}$.

The TA20 sensor head accumulates ferrous debris from the flowing lubricant, which in turn causes a flux change in the magnetic circuit. This flux change is then converted into an electrical signal, which is directly proportional to the amount of captured debris. The unit senses magnetic saturation and indicates a flush cycle where the magnet is withdrawn from the fluid line enabling the flow to clear the accumulated debris. A non-magnetic barrier between the fluid and the magnet maintains fluid line integrity. On completion of the flush cycle the magnet is then accurately repositioned in the fluid line. Bulk particulate load is measured against time and the rate of debris generation is therefore easily calculated. The output from this device is an accumulative value (until the unit flushes).

Fig. 7 shows a schematic of the equipment interconnection to the three PCs performing the data collection. One PC
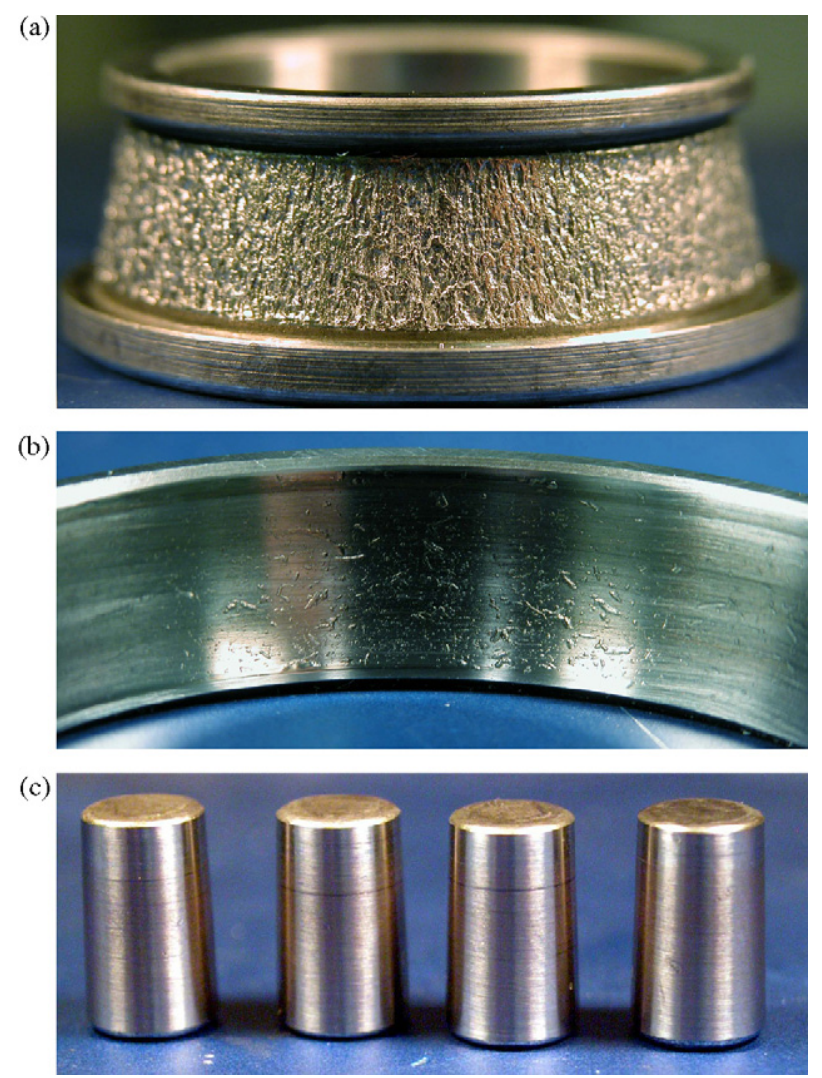

Fig. 8. Damage to components in bearing \#2 (a) inner race: extensive spallation over $75 \%$ of surface, (b) outer race: indentations from debris and (c) roller: indentations and grooves.

is used to perform on-line (real-time) analysis of the electrostatic sensors (both wear-site and oil-line) and the vibration sensor signals. The on-line processing system, developed by Smiths Aerospace, Southampton, involves both a simple statistical approach, including root mean squared (rms) calculations, and a more advanced analysis, designed to enhance charge signals related to the bearing component defect frequencies. The experimental wear-site sensor and vibration data will be presented against test time in two modes, the first will be rms, and the second will be normalised inner race defect frequency data (position of the artificial defect). This enhances data associated with fatigue wear initiated on the artificial defect site. The statistical data is produced once every two seconds, whereas the defect frequency data is produced at a rate of two points per minute.

The second PC collects and processes outputs from the two Macom units. The software, written by Macom Technologies,

Table 3

Weight loss measurements

\begin{tabular}{|c|c|c|c|c|c|c|}
\hline \multirow[t]{2}{*}{ Bearing no. } & \multicolumn{2}{|c|}{ Weight of cup (g) } & \multirow[t]{2}{*}{ Mass loss (mg) } & \multicolumn{2}{|c|}{ Weight of cone $(\mathrm{g})$} & \multirow[t]{2}{*}{ Mass loss (mg) } \\
\hline & Initial & Final & & Initial & Final & \\
\hline 1 & 61.14961 & 61.14973 & -0.12 & 116.95038 & 116.94502 & 5.36 \\
\hline 2 & 61.20197 & 61.20210 & -0.13 & 116.02158 & 115.00369 & 1017.89 \\
\hline 3 & 61.02767 & 61.02793 & -0.26 & 116.81073 & 116.80831 & 2.42 \\
\hline 4 & 61.02819 & 61.14973 & 0.36 & 116.31711 & 116.31006 & 7.05 \\
\hline
\end{tabular}


collects data every $10 \mathrm{~min}$ for the TA10 and every $5 \mathrm{~min}$ for the TA20. The third PC collects data from the thermocouple reader and stores information as the test progresses at a rate of 1 point per thermocouple per minute.

Data is also displayed in real-time by an oscilloscope and is archived using a digital audio tape (DAT) recorder, in case subsequent re-analysis of any of the test data is required.

Gravimetric analysis was also used, which involved weighing of both the cup (outer race) and cone assembly (inner race, rollers and cage) before and after testing, using a 5figure digital balance. Prior to each weighing the bearings were cleaned/degreased using solvents (1:2 mixture of cyclohexane and ethyl acetate) for $30 \mathrm{~min}$ in an ultrasonic bath.

Scanning electron micrographs (SEM) were imaged with a JSM 6500F thermal field emission scanning electron microscope.

\section{Results and discussion}

The following section will present data from a seeded-fault test (on bearing \#2) tested to failure (seizure) at a test time of $68 \mathrm{~h}$, which is characterised by the motor stopping.

\subsection{Gravimetric analysis}

Gravimetric analysis, shown in Table 3 indicates that the cone (inner race) of bearing \#2, with the artificial defect, had the vast majority of weight loss during the test, and thus likely to be the origin of the failure.

\subsection{Images of the bearing damage}

The photographic evidence clearly shows that failure of the bearings during the accelerated test originated from the inner race of bearing \#2, as shown by Fig. 8. The inner race exhibited extensive spallation of $75 \%$ of the surface. The majority of the remaining damage was caused by indentation of the other surfaces by embedment of debris produced from the inner race of bearing \#2. The other bearings also exhibited indentation damage similar to the roller and outer race of bearing \#2 but to a lesser extent.

Rig commissioning tests have already shown that during accelerated testing, fatigue failure is initiated from the artificial defect, as would be anticipated. Fig. 9 shows two previous tested bearings, with artificial defects, from different tests. The test-runs give an indication of the life of the bearing with the artificial defect during testing. The first image shows no or little perceivable damage (maximum dynamic radial load $15 \mathrm{kN}$ for $44 \mathrm{~h}$ ), while the second image clearly exhibits damage in the vicinity of the artificial defect, indicating that the defect is the initiator for failure (maximum dynamic radial load $20 \mathrm{kN}$ for $85 \mathrm{~h}$ ). Although the test conditions (commissioning and presented) are dissimilar, the mechanism is the same and by presenting tests that did not cause seizure, the progression of the current test can be visualised. (a)

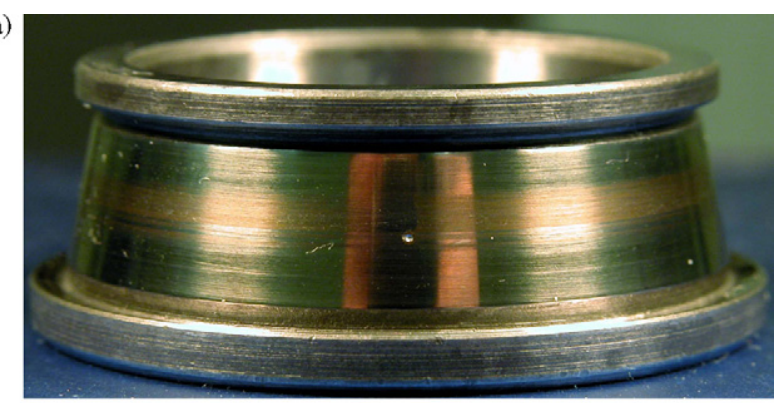

(b)

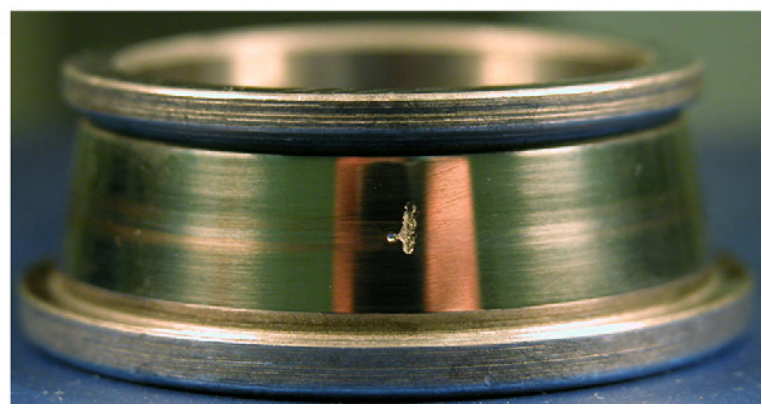

Fig. 9. Images of previous accelerated tests showing bearings with artificial defect after testing: (a) bearing \#2, test time $48 \mathrm{~h}$, maximum load $15 \mathrm{kN}$. (b) Bearing \#3, test time $85 \mathrm{~h}$, maximum load $20 \mathrm{kN}$.

\subsection{SEM images}

The SEM image of the debris obtained from the magnetic plug, see Fig. 10, shows a variety of debris sizes from tens to hundreds of microns. The larger particles generally show some cracking, probably due to crushing between the rollers and races.

Fig. 11 shows cross-section SEM images of the damage shown on the inner race of bearing \#2. As can be clearly seen sub-surface cracking is present which can produce both large and small scale fatigue debris particles.

\subsection{Oil-line analysis}

The signals from the monitoring devices employed in the oil recirculation system (thermocouple, electrostatic OLS and

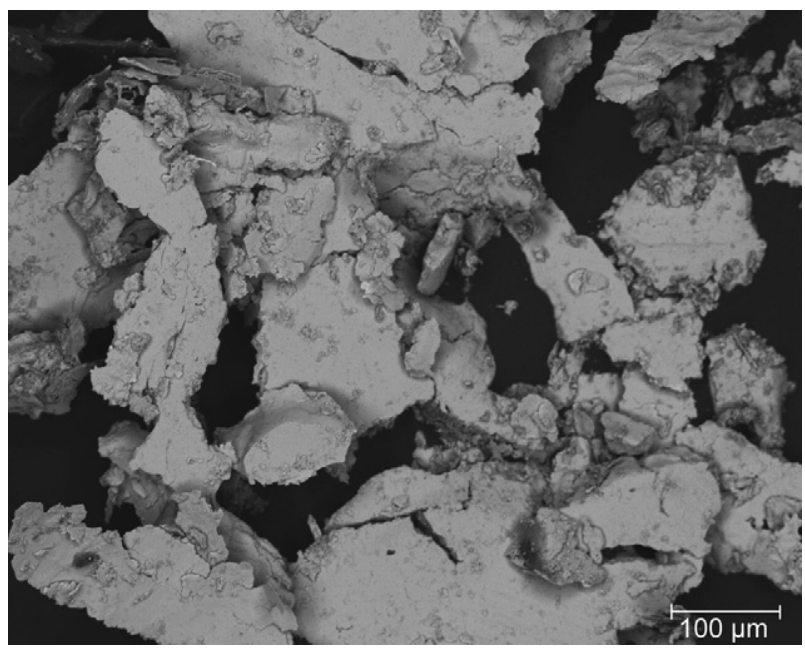

Fig. 10. Topographical SEM of debris particles collected from magnetic plug at the end of the test. 

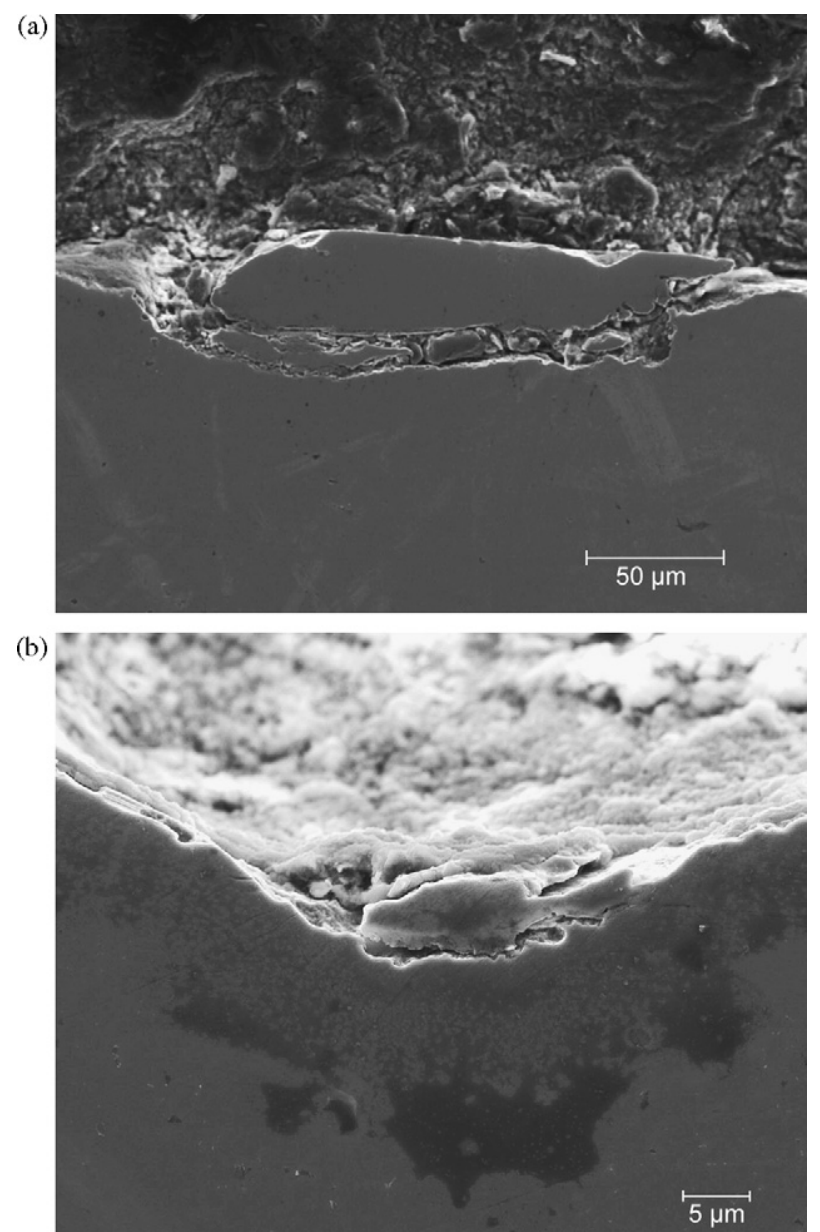

Fig. 11. SEM images cross-section of the inner race from bearing \#2 showing both large and small scale sub-surface cracking, which eventually lead to spalling.

Macom units) indicate two periods of interest as shown in Fig. 12. The first period of interest is around $50 \mathrm{~h}$ running time (49-52 h); the TA20 indicates an increase in debris production over a period of $2.5 \mathrm{~h}$, returning to a baseline level. Thermocouple data also indicates that the bearings produced larger thermal output than during normal running during this period, i.e. the bearing was running hotter than normal. This is indicated by the thermal variation between inlet and outlet temperatures.

The second and most important period of interest is that prior to failure at $68 \mathrm{~h}$ (expanded data is shown Fig. 13 for the window $60-72 \mathrm{~h}$ ); the thermocouple data indicates a steady increase in both inlet and outlet temperatures after $61.5 \mathrm{~h}$ and, sharp increases are seen in the inlet, outlet and the difference between the two about $30 \mathrm{~min}$ prior to failure, although it should be noted that there is a sudden increase $\left(0.5^{\circ} \mathrm{C}\right.$ over $\left.1 \mathrm{~min}\right)$ at $61.5 \mathrm{~h}$ running time, it is unknown if this is associated with the failure. Similar increases have also been seen during loading cycles (loading of $17.5 \mathrm{kN}$ at $24 \mathrm{~h}$ on Fig. 12). The Macom oilline sensors (TA10 and TA20) clearly detect debris production increasing from $64 \mathrm{~h}$ ( $4 \mathrm{~h}$ prior to failure), with the TA20 reaching $300 \%$ of baseline level $1 \mathrm{~h}$ later and passing its upper limit 40 min before seizure. The electrostatic oil-line sensors data also clearly indicates increased debris production $4 \mathrm{~h}$ prior to failure,

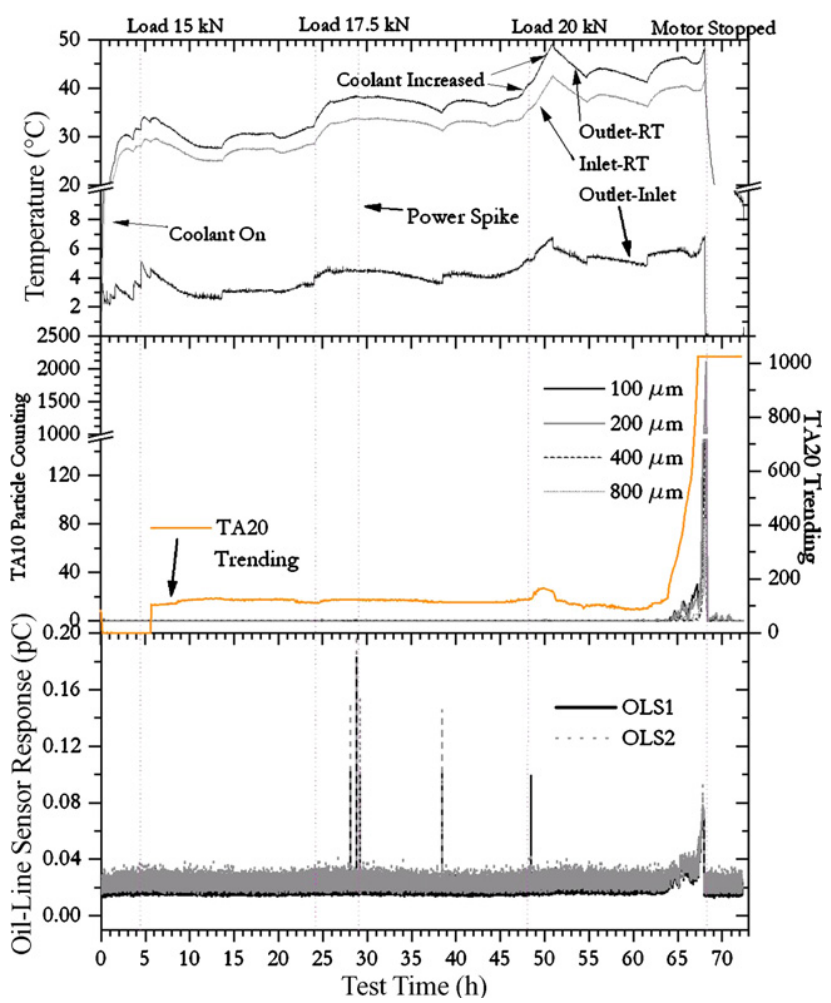

Fig. 12. Thermocouple, Macom and oil-line data (rms).

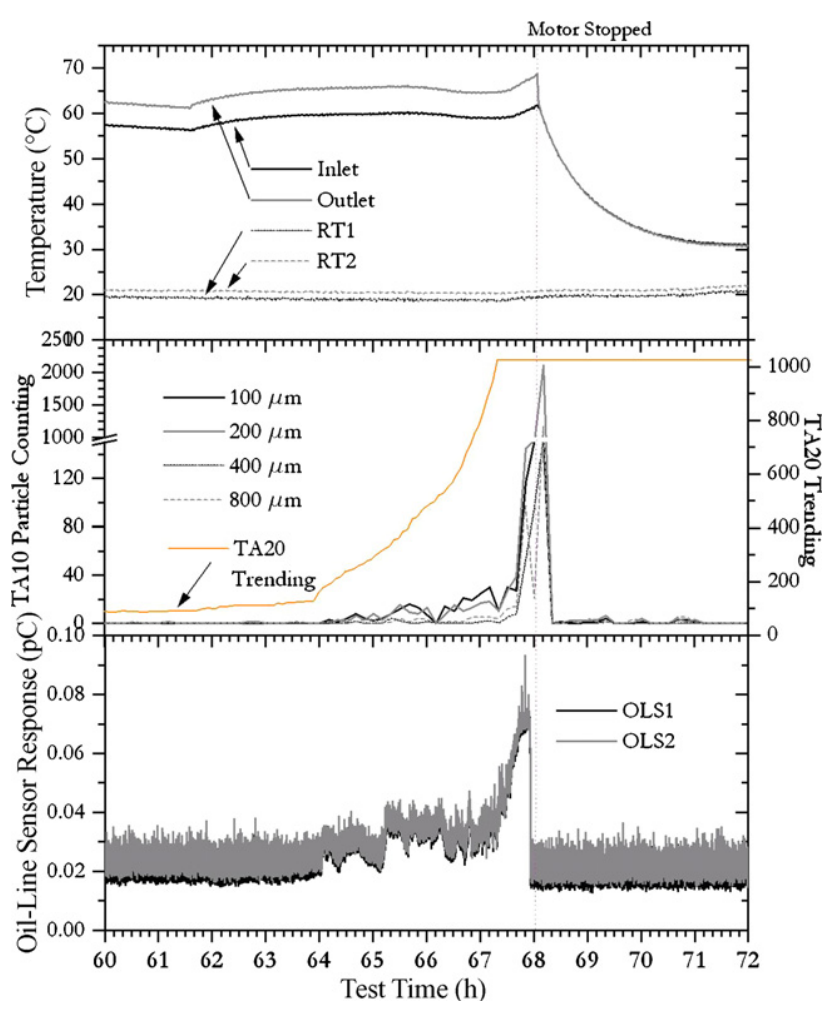

Fig. 13. Expansion of thermocouple, Macom and electrostatic oil-line data, for 60-72. 


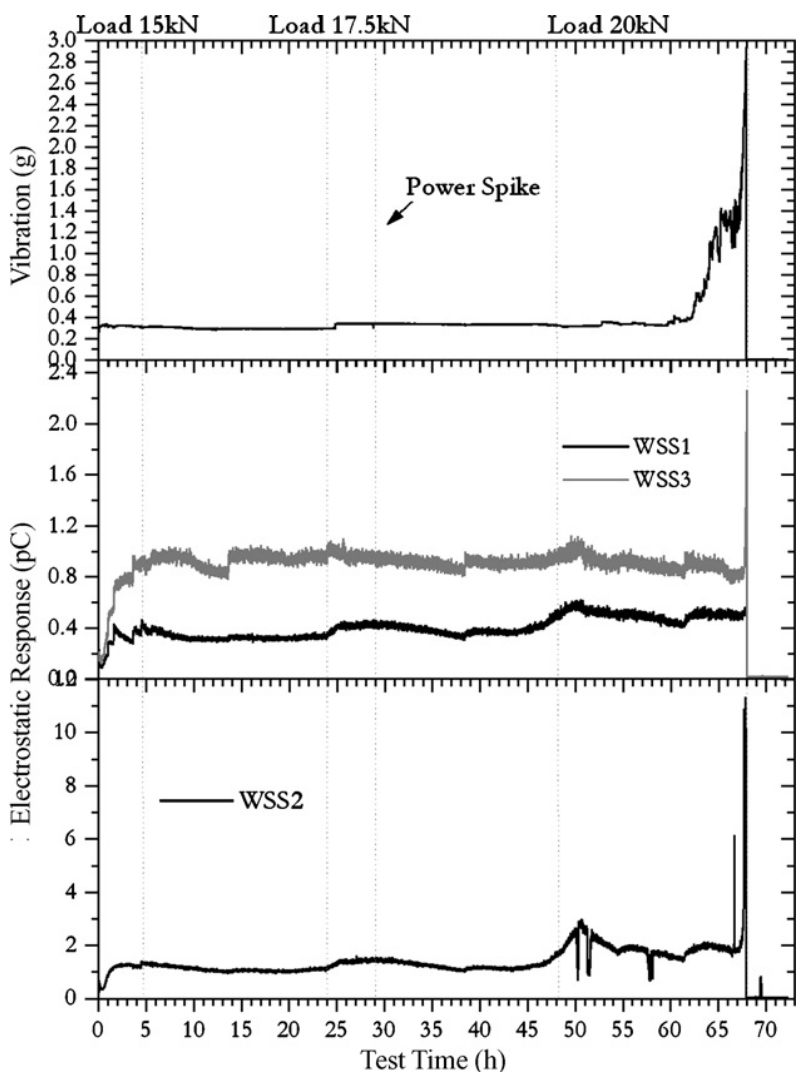

Fig. 14. Vibration and electrostatic wear-site sensor data (rms).

with significant levels $30 \mathrm{~min}$ prior to seizure (as seen for TA10 data).

\subsection{Bearing chamber monitoring}

Monitoring devices employed in/on the bearing chamber (electrostatic WSS and vibration) also indicate two periods of interest, as shown in Fig. 14, and in the same period as detected by the oil-line systems. Around $50 \mathrm{~h}$ running time (49-52 h) the electrostatic WSSs exhibit increased levels, particularly WSS 2 which shows a significant increase. This correlates with the increase in activity seen on the TA20 and the increase in inlet and outlet temperatures, as shown in the previous section, over the same period of time. Vibration data for this period indicates no sign of activity. It is unclear what the cause of this period of activity is, it could be possibly caused by an initial spallation at the artificial defect followed by some healing process, but appears not to be severely detrimental to the bearing life.

The most important period of interest is the $12 \mathrm{~h}$ prior to failure (expanded data is shown Fig. 15 for the window $60-72 \mathrm{~h}$ ). At around $61.5 \mathrm{~h}$ running time there is an increase in electrostatic signal, however this is not appreciably above background levels. From rms values (Figs. 14 and 15) all three electrostatic show no significant increase in charge level until $30 \mathrm{~min}$ prior to failure; the vibration data exhibit a clear increase from $64 \mathrm{~h}$ running time ( $4 \mathrm{~h}$ prior to failure) with a rapid increase about $30 \mathrm{~min}$ prior to seizure.

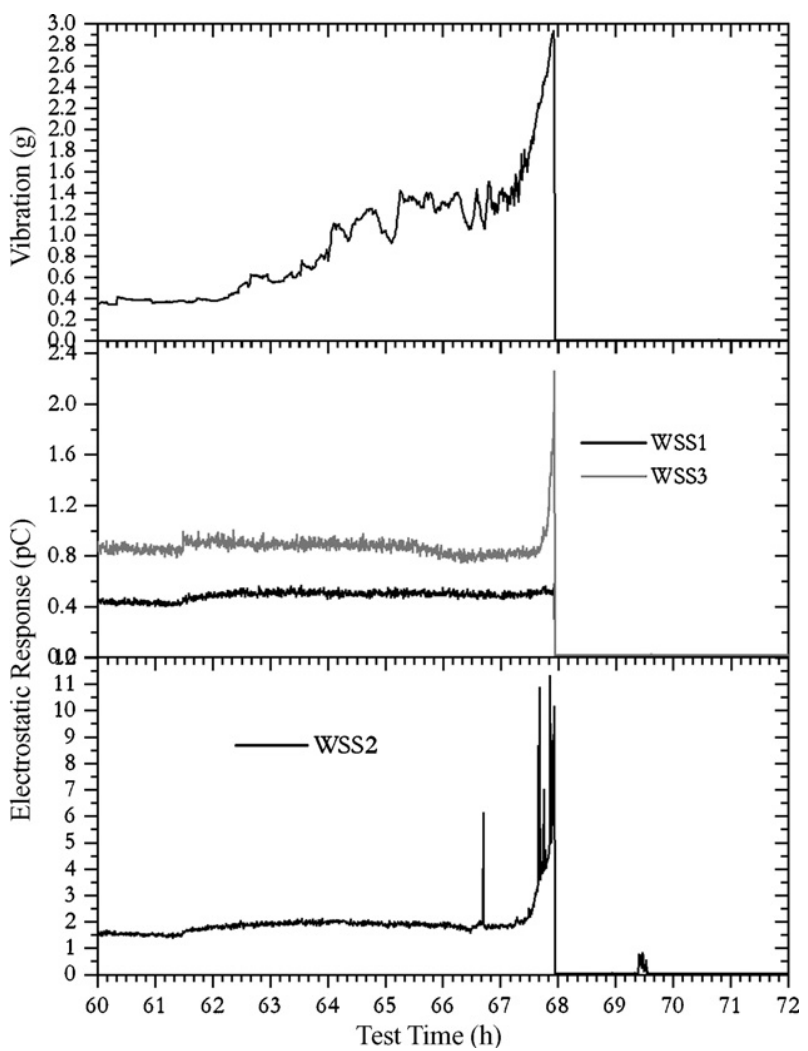

Fig. 15. Expansion of vibration and electrostatic wear-site sensor data (rms), for 60-72 $h$.

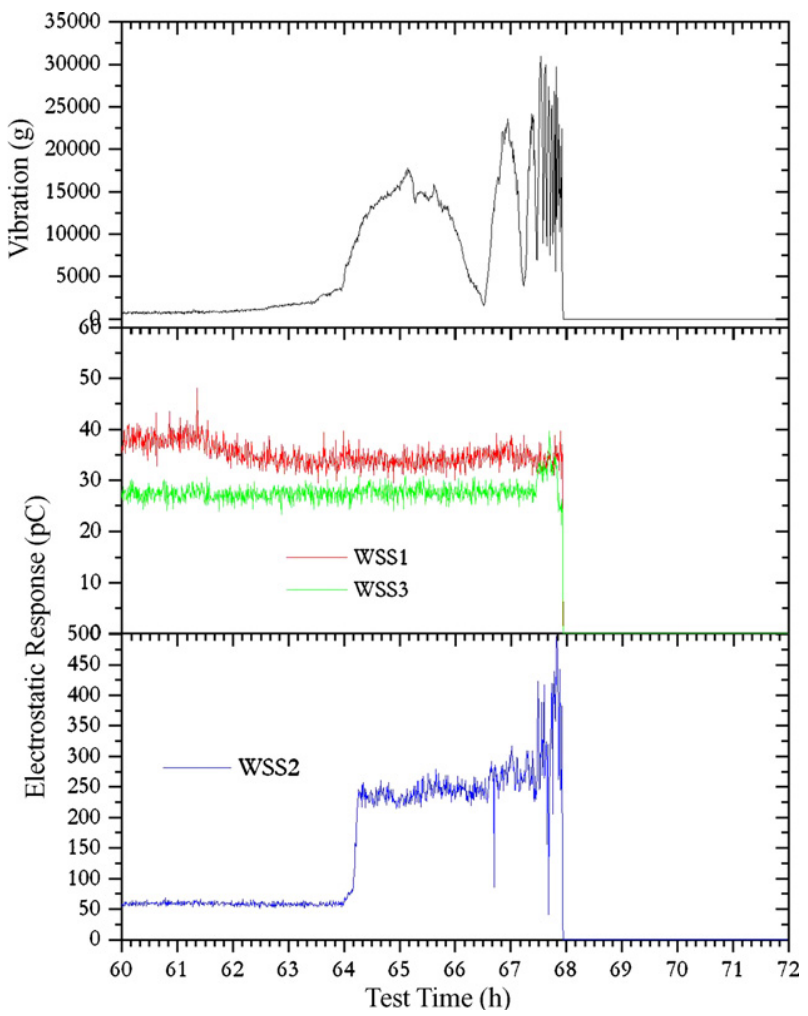

Fig. 16. Expansion of vibration and electrostatic wear-site sensor data (normalised inner race defect frequency), for 60-72 $\mathrm{h}$. 
To enhance detection, normalised inner race defect frequency has been computed: this analysis performs a Fourier transform on the data, the subsequent frequency domain data is then windowed around the component's defect frequency (calculated from the shaft rotation speed), this windowed data is averaged; this enhances sensitivity to damage of the bearing components (inner race, outer race, roller and cage). This inner race defect frequency clearly indicates significant increases at running time $64 \mathrm{~h}, 4 \mathrm{~h}$ prior to failure, for vibration and electrostatic wear-site sensor 2 (see Fig. 16). During this test it would be expected that WSS 2 would be most responsive to the early indications of test bearing degradation, as it is the closest to and senses both test bearings, whereas the other two WSSs only monitor the support bearings.

It should be noted that the WSS software has not been fully optimised and developments producing increased sensitivity to the bearing deterioration are expected in the future.

\section{Conclusions}

Numerous experiments have been conducted to optimise conditions for accelerated taper-roller bearing testing, although test data has only been presented from one test. The following conclusions can be made about the test data presented:

- Gravimetric and pictorial evidence indicates that wear initiated at or near the artificial defect on the test bearing inner race leading to eventual failure and seizure.

- Experimental data indicates two periods of activity:

- Around $50 \mathrm{~h}$ running time (49-52 h), electrostatic WSSs exhibit increased levels, particularly WSS 2; TA20 indicated increased debris production; thermocouple data indicated increased inlet and outlet temperatures.

- Prior to failure, this can be further split into three periods:

All monitoring devices detect a sharp increase 30 min prior to failure.

The debris monitoring systems (TA10, TA20 and electrostatic OLS) detect increase levels of debris production $4 \mathrm{~h}$ prior to failure. Electrostatic WSS 2 and vibration inner race defect frequencies clearly indicate bearing deterioration at this time as well.

At $61.5 \mathrm{~h}(6.5 \mathrm{~h}$ prior to failure $)$ there is a steady increase in temperature readings with a sharp increase in the difference between outlet and inlet. Also at this period in time the rms values for all three electrostatic WSS increase steadily.

- Electrostatic monitoring offers a viable alternative or complementary technique to systems already employed in bearing condition monitoring.

- Electrostatic monitoring offers sensing capabilities for both oil-line debris and wear-site in one monitoring suite.

\section{Acknowledgements}

The author(s) would like to thank the U.S. Office of Naval Research (ONR) for funding and The Timken Company, in particular Michael Hoeprich and Roger Logsdon, for supplies and valuable support before and during testing. We would also like to thank John Elderkin, local liaison for The Timken Company, for much need advice and help.

\section{References}

[1] I. Salam, A. Tauqir, A. Ul Haq, A.Q. Khan, An air crash due to fatigue failure of a ball bearing, Eng. Fail. Anal. 4 (1998) 150158.

[2] R. Barron, Engineering Condition Monitoring. Practice, Methods and Applications, Longman, 1996, ISBN 0582246563.

[3] M.J. Neale, in: E.D. Yardley (Ed.), The Principles Behind Condition Monitoring Techniques in Condition Monitoring-The Practise, Professional Engineering Publishing, 2002, ISBN 186058361X, pp. 2134.

[4] S. Morris, R.J.K. Wood, T.J. Harvey, H.E.G. Powrie, Use of electrostatic charge monitoring for early detection of adhesive wear in oil lubricated contacts, J. Tribol. Trans. ASME 124 (2002) 288296.

[5] C.J. Li, J. Ma, Wavelet decomposition of vibration for detection of bearinglocalized defects, NDT T 30 (1997) 143-149.

[6] L. Manes, J.-M. De Monicault, R. Gras, Monitoring damage by acoustic emission in bearing steels in cryogenic environment, Tribol. Int. 34 (2001) 247-263.

[7] N. Tandon, A. Choudhury, A review of vibration and acoustic measurement methods for the detection of defects in rolling element bearings, Tribol. Int. 32 (1999) 469-480.

[8] H.E.G. Powrie, K. McNicholas, Gas path condition monitoring during accelerated mission testing of a demonstrator, AIAA paper 97-2904, July 1997.

[9] H.E.G. Powrie, C.E. Fisher, Engine gas path integrity monitoring, Aerotech 94, Paper C470/6/052, January 1994.

[10] H.E.G. Powrie, C.E. Fisher, Monitoring of foreign objects ingested into the intake of gas turbine aero-engine, in: International Conference on Condition Monitoring Proceedings, University of Swansea UK, 1999, pp. 175190.

[11] O.D. Tasbaz, H.E.G. Powrie, R.J.K. Wood, Electrostatic Monitoring of Oil lubricated contacts for early detection of wear, in: Proceedings of the International Conference on Condition Monitoring, University of Wales Swansea, April, 1999.

[12] R.J.K. Wood, M. Browne, M.T. Thew, Electrostatic charging precursor to scuffing in lubricated contacts, in: Proceedings of the IMechE World Tribology Congress, London, September, 1997.

[13] O.D. Tasbaz, R.J.K. Wood, M. Browne, H.E.G. Powrie, G. Denualt, Electrostatic monitoring of oil lubricated sliding point contacts for early detection of scuffing, Wear 230 (1999) 8697.

[14] T.J. Harvey, R.J.K. Wood, Electrostatic monitoring of boundary and mixed lubrication, in: Proceedings of the Second World Tribology Congress, Proceedings of 28th Leeds-Lyon Symposium on Tribology (ISBN 0-444-50969-0), Vienna, September, 2001 (Paper A-83-11856).

[15] H.E.G. Powrie, C.E. Fisher, O.D. Tasbaz, R.J.K. Wood, Performance of an electrostatic oil monitoring system during an FZG gear scuffing test, in: Proceedings of the International Conference on Condition Monitoring, University of Wales Swansea, April, 1999.

[16] H.E.G. Powrie, R.J.K. Wood, T.J. Harvey, S. Morris, Re-analysis of electrostatic wear-site sensor data from FZG gear scuffing tests, Condition Monitor, 177 (2001) 6-12, ISSN 0268-8050.

[17] H.E.G. Powrie, C.E. Fisher, Engine health monitoring: towards total prognostics, in: IEEE Aerospace Conference Proceedings 1999, 
Snowmass at Aspen, Colorado, March, 1999, ISBN 0-7803-54273.

[18] H.E.G. Powrie, Use of electrostatic technology for aero engine oil system monitoring, in: IEEE Aerospace Conference Proceedings, Big Sky, Montana, 2000, ISBN 0-7803-5847-3.
[19] H.E.G. Powrie, Electrostatic charge generation associated with machinery deterioration, in: IEEE Aerospace Conference Proceedings, Big Sky, Montana, 2002, ISBN 0-7803-7232-8.

[20] http://www.macomtech.net. 